\title{
A case study of sea breeze blocking regulated by sea surface temperature along the English south coast
}

\author{
J. K. Sweeney ${ }^{1}$, J. M. Chagnon ${ }^{2,}$, and S. L. Gray ${ }^{1}$ \\ ${ }^{1}$ Department of Meteorology, University of Reading, Reading, Berkshire, UK \\ ${ }^{2}$ National Centre for Atmospheric Science, University of Reading, Reading, Berkshire, UK \\ * current address: Department of Earth, Ocean, and Atmospheric Science, Florida State University, Tallahassee, Florida, USA
}

Correspondence to: J. M. Chagnon (jchagnon@fsu.edu)

Received: 6 August 2013 - Published in Atmos. Chem. Phys. Discuss.: 24 September 2013

Revised: 28 January 2014 - Accepted: 18 February 2014 - Published: 6 May 2014

\begin{abstract}
The sensitivity of sea breeze structure to sea surface temperature (SST) and coastal orography is investigated in convection-permitting Met Office Unified Model simulations of a case study along the south coast of England. Changes in SST of $1 \mathrm{~K}$ are shown to significantly modify the structure of the sea breeze immediately offshore. On the day of the case study, the sea breeze was partially blocked by coastal orography, particularly within Lyme Bay. The extent to which the flow is blocked depends strongly on the static stability of the marine boundary layer. In experiments with colder SST, the marine boundary layer is more stable, and the degree of blocking is more pronounced. Although a colder SST would also imply a larger land-sea temperature contrast and hence a stronger onshore wind - an effect which alone would discourage blocking - the increased static stability exerts a dominant control over whether blocking takes place. The implications of prescribing fixed SST from climatology in numerical weather prediction model forecasts of the sea breeze are discussed.
\end{abstract}

\section{Introduction}

A sea breeze is a mesoscale circulation driven by the differential heating of land and sea surfaces. It is characterized by a surface flow from the sea towards the land, and a deeper, weaker return flow aloft. Sea breezes have been extensively studied worldwide due to their daily recurrence in many regions of dense human population. They are of particular interest to air-quality control bodies and many marine and littoral industries. Miller et al. (2003) review the large range of geophysical factors upon which the sea breeze depends, including surface temperature variation, diffusion of heat, topography, acoustic wave propagation, the Coriolis force, static stability, and the synoptic-scale flow. In this paper we demonstrate the critical dependence of sea breeze structure on sea surface temperature (SST) for a case study on the English south coast.

The land-sea temperature difference is one of the most important factors influencing sea breeze development, and without it the sea breeze would not form. The large amplitude of the diurnal heating of the land surface is well known. However, changes in sea surface temperature also play a strong role in air-sea interaction (Kawai and Wada, 2007). Any variability in the sea surface temperature (SST) over timescales of months, weeks, days and even hours impacts the atmospheric boundary layer and may affect sea breeze formation.

Early numerical studies of the sea breeze demonstrated a relative lack of sensitivity of the sea breeze to SST in low wind conditions (Segal and Pielke, 1985). Arritt (1987) concluded that, as long as the surface layer over the water body remains stably stratified, then the water temperature does not make a difference to the sea breeze. More recent studies have concluded that the impact of SST on the sea breeze is stronger than was previously thought. Kawai et al. (2006) investigated the effect on the surface wind field of a diurnal variation in SST within Mutsu Bay, Japan - a semi-enclosed sea. Diurnal SST variation is climatologically high in most semi-enclosed to fully enclosed seas such as the Mediterranean, the Arabian Sea, the Sea of Okhotsk and the Sargasso Sea. In conditions of high insolation and weak gradient wind speed the diurnal amplitude of the SST in Mutsu 
Bay is large, up to $5 \mathrm{~K}$ in some areas. Due to this, Kawai and Wada (2007) estimated that the simulated heat flux from the ocean is underestimated by an average of $10 \mathrm{Wm}^{-2}$ by midday if SST is held constant. Kawai et al. (2006) analyzed SSTs from NOAA AVHRR satellite retrievals and in situ buoy data and found that for over $80 \%$ of the days between April and September when the diurnal SST signal exceeded $1.0 \mathrm{~K}$ the daytime upslope wind speed remained below $5.0 \mathrm{~ms}^{-1}$. By comparing numerical simulations of the sea breeze with and without a coupled mixed-layer ocean model, Kawai et al. (2006) demonstrated that, while the sea breeze circulation does not change structurally, the circulation was weaker in the coupled diurnally varying SST run than in the uncoupled fixed SST control run.

Tang (2012) investigated the effect of hourly updated SST in a convection-permitting numerical model simulation of the sea breeze in the southern UK. The SST from a shelf sea model was on average $1.5 \mathrm{~K}$ warmer than the fixed values of a control run in which the SST was initialized with Operational Sea Surface Temperature and Sea Ice (OSTIA; Donlon et al., 2011) data. The consequences of a warmer SST were a weaker sea breeze, a less stable marine boundary layer, and less fog and mist. Tang (2012) presented this case study as evidence that short-term forecasts could be improved if operational regional-scale numerical weather prediction (NWP) models such as the Met Office Unified Model (MetUM) incorporated diurnally varying SST.

The objective of this study is to determine the sensitivity of the sea breeze along the English south coast to SST and coastal orography. While previous studies have investigated the effect of orography on the sea breeze (e.g., Porson et al., 2007), the combined effect of SST and orography presented in this paper is novel. At present, the Met Office prescribes climatological SSTs (i.e., long-term monthly mean) with no diurnal variation in their regional-scale operational NWP forecasts. As in Tang (2012), a motivation for performing the analysis described in this paper is to determine what errors in sea breeze structure result from prescribing fixed SST. To accomplish this goal, hindcasts for a case study day, 8 August 2010, are generated using the MetUM. In a control run the SST field is held constant. Additional experiments are performed using SST fields perturbed from the control values, with and without coastal orography. Sea breeze dynamics and characteristics - including timing, strength, direction and depth - are analyzed for each hindcast. The paper is organized as follows. The methodology is described in Sect. 2, including a description of the case study region and the design of numerical experiments. An overview of the synoptic conditions on the day of the case study is presented in Sect. 3. In Sect. 4, the sea breeze in a control simulation with unperturbed SST is described, and in Sect. 5 simulations of the sea breeze with perturbed SST, with and without coastal orography, are compared. The results and implications for short-term NWP forecasts are discussed in Sect. 6.

\section{Methodology}

\subsection{Case study location}

The analysis presented in this paper focuses on a stretch of coastline in southern England surrounding Weymouth $\left(58.62^{\circ} \mathrm{N}, 2.62^{\circ} \mathrm{W}\right)$. The coastal topography in the vicinity of Weymouth and the locations of two observational platforms, Lyme Bay and Portland Harbour, are shown in Fig. 1a. At both locations, the Channel Coastal Observatory provided wind speed and direction observations that were used in this investigation to evaluate the numerical model simulations. The platform labeled "Portland Harbour" is located on a breakwater on the southeast side of the Isle of Portland - a large promontory approximately $6 \mathrm{~km}$ long and $2.5 \mathrm{~km}$ wide extending south of Weymouth (not marked on the map). The orography to the northwest of Weymouth consists of hills of approximately $150 \mathrm{~m}$ elevation. To the northeast of Weymouth, the topography of the mainland is relatively flat.

Weymouth Bay is shallow, with a maximum depth of $25 \mathrm{~m}$. It faces southeast and is approximately $12.5 \mathrm{~km}$ wide. It is not a semi-enclosed sea (like Mutsu Bay that was studied by Kawai and Wada, 2007), but the shallow depth and small dimensions suggest a potential for large diurnal SST variations (see Sect. 2.2). The prevailing winds are in the south to west quadrant, and occur $61 \%$ of the year (Risien, 2013).

Lyme Bay lies to the west of the Isle of Portland. It is an open bay facing south, approximately $55 \mathrm{~km}$ wide. Eastern Lyme Bay, adjacent to the Isle of Portland, has an approximately straight coastline facing southwest. The orography rises steeply to $160 \mathrm{~m}$ a.s.l.

\subsection{Numerical model description}

The MetUM version 7.3 is employed for this study. The MetUM solves the fully compressible, nonhydrostatic equations of motion using a semi-Lagrangian, semi-implicit time integration scheme with a fifth-order-accurate spatial differencing scheme on an Arakawa-C grid with a terrain following vertical coordinate (Davies et al., 2005). The model is run with a full suite of parameterization schemes including a mixed phase microphysics scheme (Wilson and Ballard, 1999), the MOSES-II boundary layer scheme (Lock et al., 2000), and the Gregory-Rowntree mass-flux convection scheme (Gregory and Rowntree, 1990). Orography in the model is derived from the GLOBE (The Global Land One$\mathrm{km}$ Base Elevation) data set.

In this project the MetUM is configured as an atmosphereonly series of nested model runs: a global run, a $12 \mathrm{~km}$ horizontal grid spacing run over the North Atlantic European (NAE) domain, a $4 \mathrm{~km}$ horizontal grid spacing run over a UK-only domain, and a $1 \mathrm{~km}$ horizontal grid spacing run centered on the English Channel, as depicted in Fig. 1b. The presentation of results in Sects. 4 and 5 focusses on the simulations run with $1 \mathrm{~km}$ grid spacing. In the configuration that 


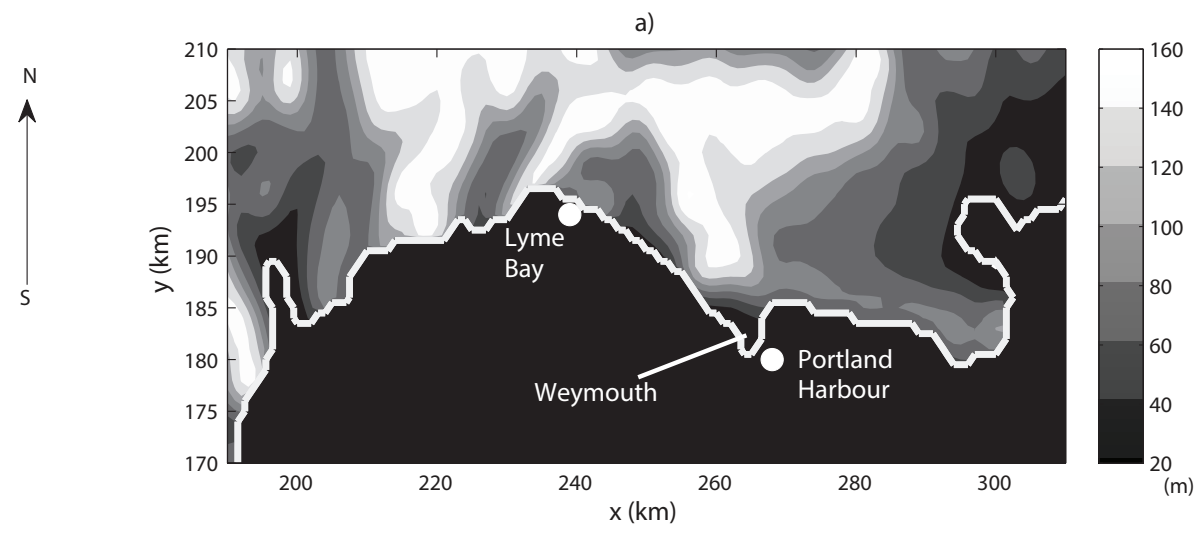

b)

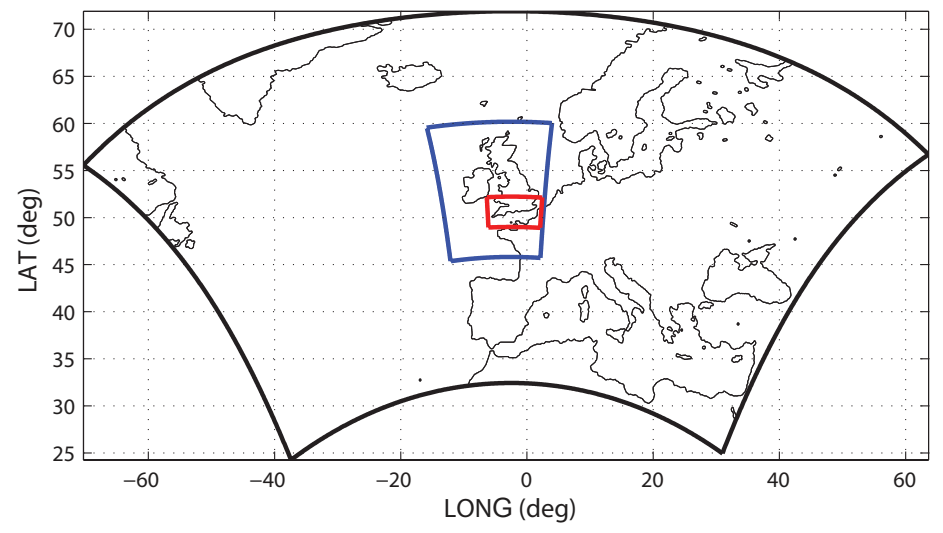

Fig. 1. (a) Orography in the vicinity of Weymouth as used in the $1 \mathrm{~km}$ grid spacing MetUM simulation (note this is a subregion of the full domain used in the $1 \mathrm{~km}$ simulation). (b) An approximation of the nested model domains. The area enclosed by the black border is the $12 \mathrm{~km}$ grid spacing North Atlantic European (NAE) domain, the blue border encloses the $4 \mathrm{~km}$ grid spacing UK domain, and the red border encloses the $1 \mathrm{~km}$ grid spacing English Channel domain. The locations of the Portland Harbour and Lyme Bay observational platforms are depicted by the white circles in panel (a) (data shown in Fig. 5).

uses $1 \mathrm{~km}$ grid spacing, the convection scheme is disabled. The larger domains provide the lateral boundary conditions for the smaller domains, with the initial and lateral boundary conditions for the NAE domain sourced from the global run. The NAE domain covers $7200 \mathrm{~km}$ by $4320 \mathrm{~km}$ with 38 vertical levels; the $4 \mathrm{~km}$ grid spacing simulation covers $1600 \mathrm{~km}$ by $1120 \mathrm{~km}$ across the UK with 38 levels; the $1 \mathrm{~km}$ grid spacing simulation covers $600 \mathrm{~km}$ by $360 \mathrm{~km}$ with 76 levels. The model top is located $39.2 \mathrm{~km}$ a.g.l. The $12 \mathrm{~km}$ grid spacing run begins at 12:00 UTC on 7 August 2010, the UK domain run with $4 \mathrm{~km}$ grid spacing begins at 00:00 UTC on $8 \mathrm{Au}-$ gust 2010 and the $1 \mathrm{~km}$ grid spacing run begins at 06:00 UTC on the same day. The initialization times are offset in order to allow for the model at each resolution to "spin up" smallerscale structures.

Numerical experiments are performed with the $1 \mathrm{~km}$ grid spacing configuration using three different SST fields to assess the sensitivity of the sea breeze to changes in SST. Each is derived from the daily $0.5^{\circ}$ OSTIA data set interpolated onto the $1 \mathrm{~km}$ grid. The three SST fields are (a) the OSTIA
SST without perturbation, (b) the OSTIA SST plus a $1 \mathrm{~K}$ uniform temperature perturbation, and (c) the OSTIA SST minus a $1 \mathrm{~K}$ uniform temperature perturbation. After initialization SST is constant throughout each model run. Figure 2a shows the unperturbed OSTIA SST field in the $1 \mathrm{~km}$ domain. Each of these three experiments is performed both with and without orography. In the experiments without orography, the elevation of the lower boundary is set to $0 \mathrm{~m}$ a.s.l. everywhere in the $1 \mathrm{~km}$ domain. A total of six numerical experiments are therefore performed in the $1 \mathrm{~km}$ domain. The experiment with unperturbed OSTIA SST and unperturbed orography is hereafter referred to as the control experiment and is analyzed in Sect. 4; the perturbed experiments are examined in Sect. 5 .

A comparison of the numerical experiment SST values and the observations for the case study day is shown in Fig. $2 b$. The observations of the Weymouth waverider buoy - located on the western shore of Weymouth (see Fig. 1a) - measured SST during the day ranging from $290.2 \mathrm{~K}$ to $290.5 \mathrm{~K}$. The OSTIA value is slightly cooler than the observations. It 
a)

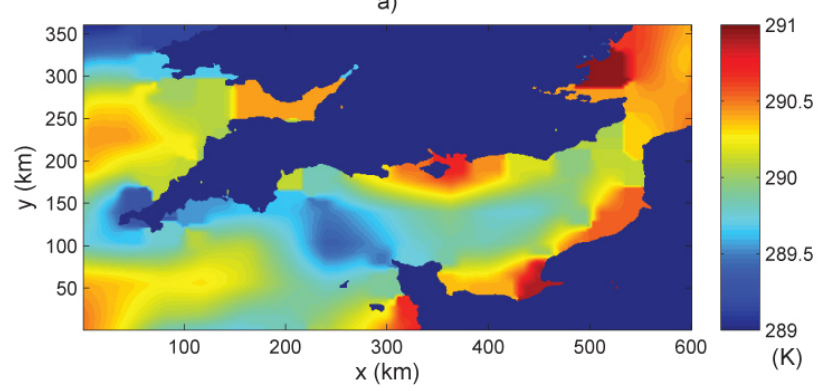

b)

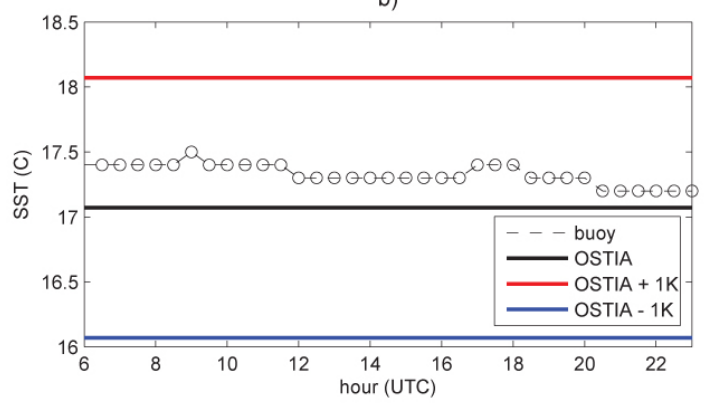

c)

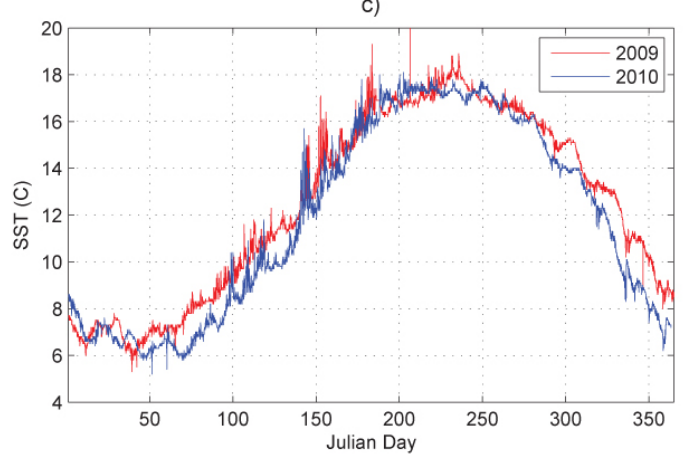

Fig. 2. (a) OSTIA SST in the $1 \mathrm{~km}$ MetUM domain. (b) Observed SST from the Weymouth waverider buoy (black circles) and SST used in simulations (solid lines) as a function of time on the day of the case study. (c) Observed SST during the years 2009 and 2010 from the Weymouth waverider buoy. (Waverider buoy data supplied by the Channel Coastal Observatory.)

should be noted that the model SST values shown in Fig. 2b apply only to the grid box nearest the waverider buoy, and the relative differences between observations and model may not hold across the entire domain. Furthermore, the diurnal variation of SST should lead to a larger cold bias in the OSTIA SST in the afternoon. Figure $2 \mathrm{c}$ presents the observed SST over 2 years at this buoy. Monthly variations are typically about $2 \mathrm{~K}$, and the diurnal variation occasionally exceeds $1 \mathrm{~K}$. The $2 \mathrm{~K}$ range of SST values prescribed in the numerical experiments performed in this study is therefore representative of the SST error that may result when SST is prescribed using diurnally fixed climatological values. It should also be noted that the southward-facing hills in the runs with orography warm by $0.2-0.5 \mathrm{~K}$ more than the flat a)

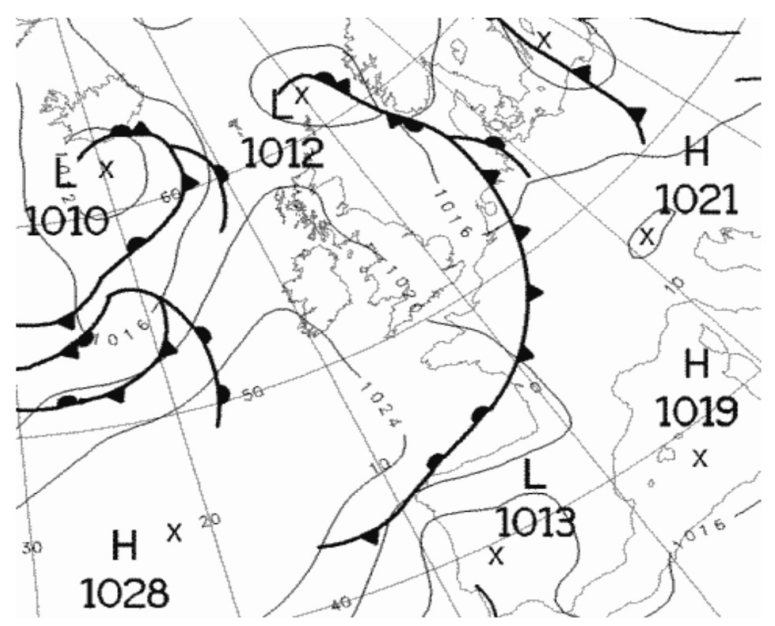

b)

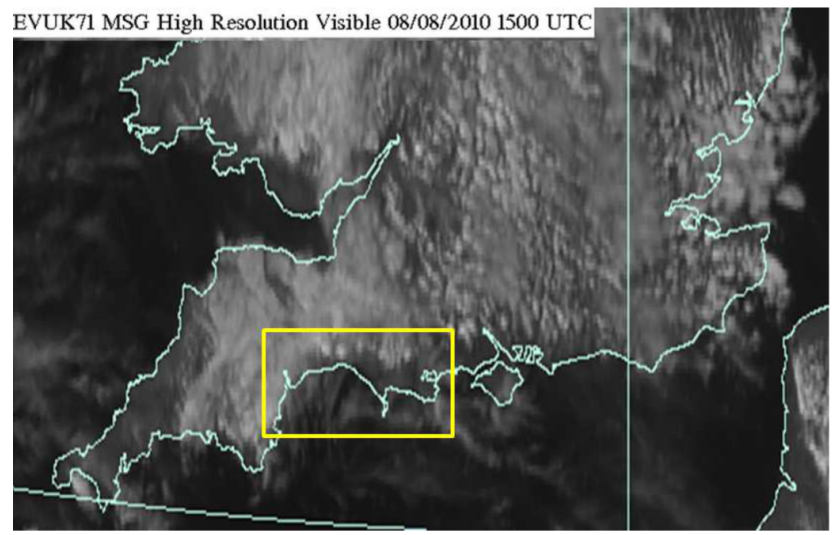

Fig. 3. (a) Met Office surface analysis valid at 00:00 UTC on 8 August 2010. (b) Visible satellite image over southern UK at 15:00 UTC on 8 August 2010. The yellow box in panel (b) corresponds to a subdomain of the MetUM simulations run with $1 \mathrm{~km}$ grid length that are presented in Sects. 4 and 5. Images courtesy of the Met Office (Crown Copyright).

land in the runs without orography. For a given SST, the land-sea temperature difference is therefore slightly larger in the runs with orography. This small difference does not complicate the analysis of sea breeze structure that is presented in Sect. 4.

\section{Case study overview}

This case was chosen as a typical example of a day on which a sea breeze developed along the south coast of England in light gradient winds and clear sky conditions. Synoptic and in situ meteorological observations for the case study are described in this section. The surface pressure analysis chart for 00:00 UTC is shown in Fig. 3a. The synoptic situation on 

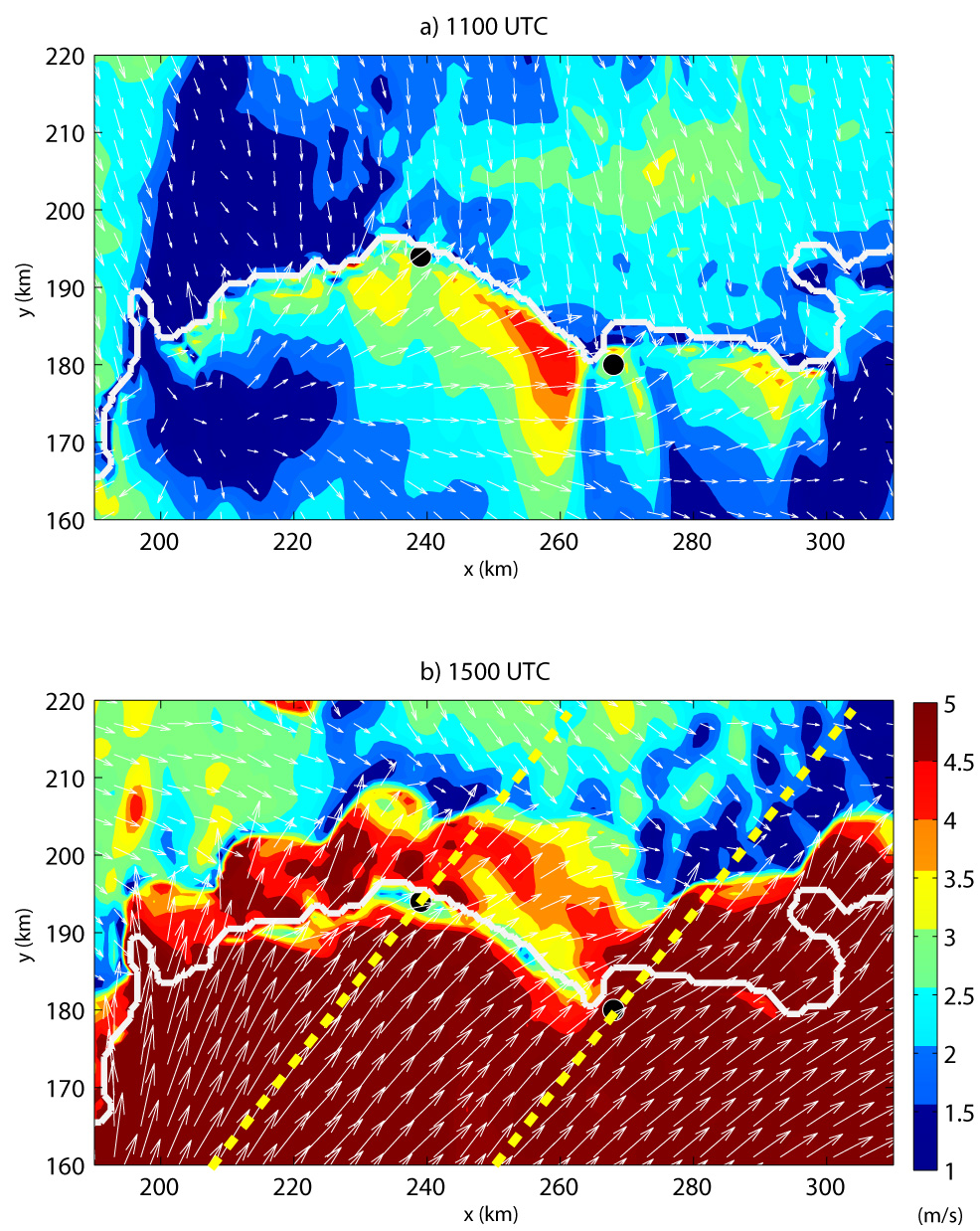

Fig. 4. Wind speed (filled contours) and wind vectors at $10 \mathrm{~m}$ a.g.1. in the control simulation valid at (a) 11:00 UTC and (b) 15:00 UTC. The black circles depict the location of the Portland Harbour and Lyme Bay observational platforms (Fig. 1a), and the yellow dashed lines correspond to the sections in Figs. 7 and 8.

8 August 2010 was characterized by an area of high pressure to the southwest of the UK, with an associated ridge that extended towards both Scotland and western France. The geostrophic wind for Weymouth on the English south coast was light northerly. The synoptic-scale pressure gradient weakened slightly during the day (not shown).

A visible satellite image of the southern UK at 15:00 UTC on the case study day indicates a sea breeze on the south coast (Fig. 3b). This image shows cloud cover over most inland areas of England. Some cirrus existed over the southwest of the UK in the early morning, with shallow cumulus clouds developing after sunrise. When a sea breeze circulation is established the sea breeze inflow rises at the sea breeze front generating convective cumulus clouds; the descending air of the return flow is dry, causing clear skies over the sea. The clear air over the English Channel adjacent to the coast is indicative of a sea breeze circulation with a sea breeze front likely to be present at the boundary between the clear skies and the cumulus clouds. The inshore extent of the sea breeze can be estimated by the width of clear skies from the shoreline towards inland areas along the south coast. The sea breeze front penetrates approximately 15 to $20 \mathrm{~km}$ onshore from Lyme Bay at this time, which is similar to the inland penetration simulated by the MetUM (see following section).

\section{Control simulation}

Model output for the control experiment shows a clear sea breeze signal along the south coast on 8 August 2010. Figure 4 depicts the $10 \mathrm{~m}$ a.g.l. surface winds in a subdomain of the $1 \mathrm{~km}$ grid domain around Weymouth. The 11:00 UTC wind field (Fig. 4a) shows the beginning of the sea breeze circulation. An area of light winds of variable direction exists off the coast. Inshore at Weymouth there is a south to southwesterly flow at the coast. This inflow is met by a weaker but more uniform north-northwesterly flow over the 

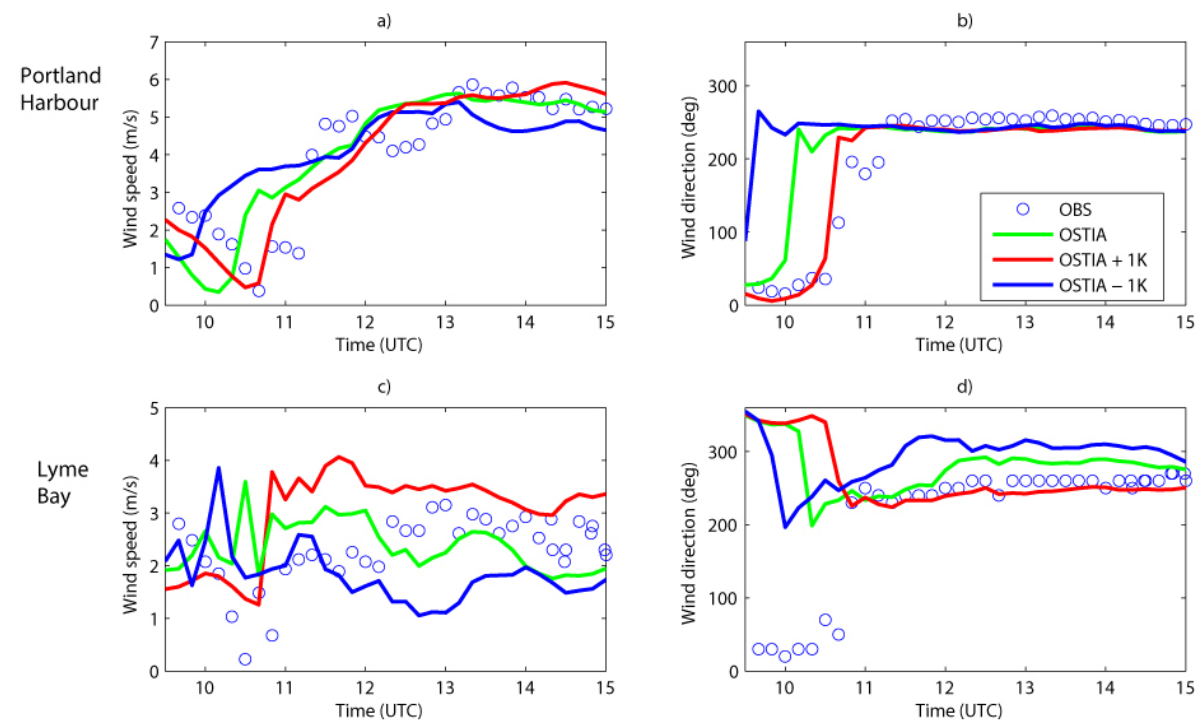

Fig. 5. A comparison of observed and simulated $10 \mathrm{~m}$ wind speed and direction at the Portland Harbour and Lyme Bay observational platforms. Modeled and observed data are plotted at $10 \mathrm{~min}$ intervals. (Data supplied by the Channel Coastal Observatory.)
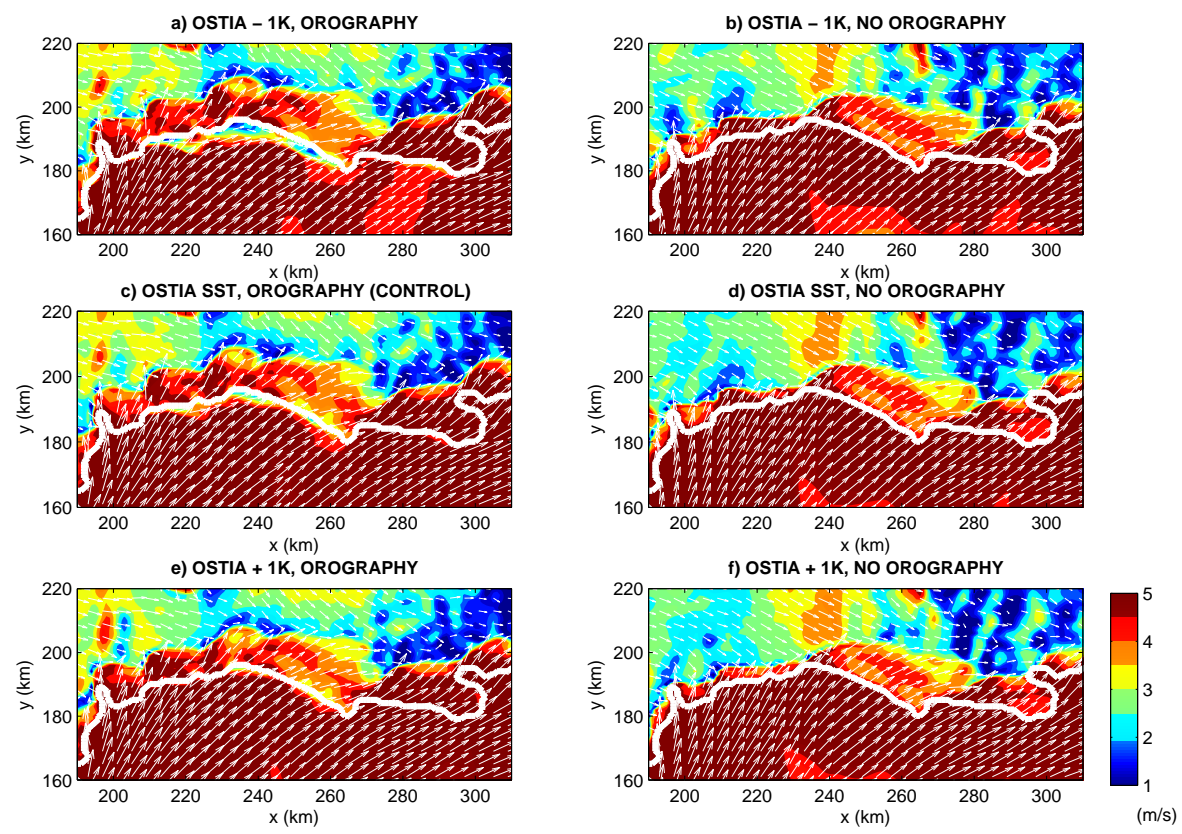

Fig. 6. Wind speed (filled contours) and vectors at $10 \mathrm{~m}$ a.g.1. at 15:00 UTC (as in Fig. 4) for the perturbed-SST experiments, with and without orography. (c) is identical to Fig. 4b but is included to enable direct comparison with the perturbed experiments.

land. The line of convergence of these two flows is the sea breeze front.

At 15:00 UTC (Fig. 4b) the sea breeze is well established, with both the offshore and inshore extent increased. The inland penetration of the sea breeze front is approximately 15$20 \mathrm{~km}$ at most locations along the coast. Offshore, the sea breeze becomes a nearly uniform southwesterly flow as the circulation strengthens, deepens, and aligns perpendicular to the landmass of England rather than localized land features.
The sea breeze strength is reasonably consistent across the sea with one notable exception in Lyme Bay. The exception is a narrow region of weaker surface winds located immediately offshore. This feature is hereafter referred to as the "calm zone". The zone of reduced wind speed is apparent during the early stages of sea breeze onset and subsequently amplifies in concert with the sea breeze itself. A calm zone associated with the sea breeze has been identified in previous investigations (Pett and Tag, 1984; Steele et al., 2013), 
but the mechanism of formation was not associated with orographic blocking as found here. In these previous studies, an offshore calm zone formed due to the interaction of the sea breeze with the gradient wind.

Figure 5 presents a comparison of $10 \mathrm{~m}$ a.g.l. wind time series between observations and simulations at the grid points nearest to Portland Harbour and Lyme Bay. Although the time series for all six numerical simulations are shown in this figure, discussion of the perturbation experiments is deferred to Sect. 5. At both locations, the wind speed and direction both prior to and following the sea breeze onset are very similar in the observations and control simulation. The wind strength behind the sea breeze front is twice as strong at Portland Harbour (approximately $6 \mathrm{~ms}^{-1}$ ) as at Lyme Bay (approximately $3 \mathrm{~ms}^{-1}$ ). The reduced wind speed at Lyme Bay, seen in both observations and simulation, is due to the presence of the calm zone near the shore (see Fig. 4b). The most discernible difference between the control simulation and observations is seen in the timing of the sea breeze onset. At both locations, the sea breeze front in the simulations leads the observations by approximately $45 \mathrm{~min}$.

\section{Simulations with perturbed SST and smoothed orography}

As discussed in the previous section, Fig. 5 presents $10 \mathrm{~m}$ a.g.l. winds in Portland Harbour and Lyme Bay in observations and in the three experiments with perturbed SST and unperturbed orography. The numerical experiment with the warmest SST field (red curves) has the latest sea breeze onset time, and the experiment with the coolest SST (blue curves) has the earliest, which is consistent with Miller et al. (2003, their Eq. 4). At Portland Harbour, the perturbation of SST affects the sea breeze onset time but does not have a very strong effect on the wind strength and direction after the passage of the front. At Lyme Bay, which lies within the calm zone (see Fig. 4b), the simulations with warmer SST produce a stronger wind than the simulations with cooler SST. In other words, a smaller land-sea temperature contrast results in a stronger wind speed immediately offshore in Lyme Bay following the passage of the sea breeze. This counterintuitive result is a consequence of the sea breeze circulation being partially blocked by the coastal orography, as will be demonstrated in the remainder of this section.

A comparison of the $10 \mathrm{~m}$ a.g.l. winds in the six experiments with perturbed SST and orography is presented in Fig. 6. The presence of a calm zone offshore in Lyme Bay is only evident in the runs with orography (left column, Fig. 6). The runs without orography (right column, Fig. 6) produce a more uniform wind field offshore, and there is no evidence of a calm zone. The run with the coolest SST and orography (Fig. 6a) produces a calm zone that is broader and more pronounced than in the control run (Fig. 6c), which in turn has a calm zone that is broader and more pronounced than in the run with warmest SST (Fig. 6e). The effect of SST alone on the surface structure of the sea breeze in the absence of orography is not very pronounced, as can be seen by comparing the perturbed SST experiments without orography (compare panels Fig. 6b, d, and f).

The time of sea breeze onset as a function of distance from shore along the sections through Lyme Bay and Portland Harbour marked in Fig. 4b is presented in Fig. 7, along with snapshots of $10 \mathrm{~m}$ a.g.l. wind speed along these sections at 15:00 UTC. The time of sea breeze onset is defined at each point in the section as the first time when wind speed exceeds $2 \mathrm{~ms}^{-1}$. Changing the value of the threshold between 1 and $3 \mathrm{~ms}^{-1}$ does not change the speed or uniformity of the offshore propagation (not shown), although the onset time is delayed; this is due to the large gradient in wind speed at the sea breeze front. (The inland propagation speed of the sea breeze can be defined as the speed at which the sea breeze front advances inland; Finkele, 1998). The speed of the extension of the sea breeze circulation can be inferred from the slope of the curves in Fig. 7a and c and appears approximately constant in each direction from the grid box of earliest onset. The offshore propagation speed is faster than the onshore propagation speed, as noted by Finkele (1998).

The wind speeds at 15:00 UTC in the Lyme Bay and Portland Harbour sections are shown in Fig. $7 \mathrm{~b}$ and $\mathrm{d}$. In the Portland Harbour section, the sea breeze front is advanced farther inland and the offshore wind speed is approximately $1 \mathrm{~ms}^{-1}$ stronger in the experiments with orography compared to those without orography; there is no systematic temperature dependence on offshore wind speeds. In the Lyme Bay section, the calm zone is evident within the first $10 \mathrm{~km}$ offshore in the experiments with orography and does not extend onshore. The calm zone is stronger in the runs with colder SST. In the runs without orography, no such decrease in offshore wind speed is evident. Changing the SST does not lead to a significant change in the overall strength of the sea breeze, but it can significantly modify the structure of the sea breeze, as demonstrated below.

Figure 8 presents vertical cross sections of the sea breeze circulation through Lyme Bay. In all experiments, the sea breeze circulation is characterized by a region of inflow near the surface and a return flow aloft. The top of the leading edge of the sea breeze front is elevated relative to the rest of the sea breeze front. In the experiments without orography (Fig. 8b, d, f), the height of the interface slopes gently downwards for the first $10 \mathrm{~km}$ or so behind the elevated sea breeze front. In the experiments with orography (Fig. 8a, c, e), there is a secondary jump in the elevation of the interface in the vicinity of the shoreline. This secondary jump is associated with airflow over the coastal topography. Furthermore, a shallow region of reduced wind speeds (i.e., the calm zone) is evident immediately offshore which is not present in the runs without orography. This shallow region of stagnation is more pronounced in the run with cold SST (Fig. 8a) than in the run with warm SST (Fig. 8e). The inland air temperature 

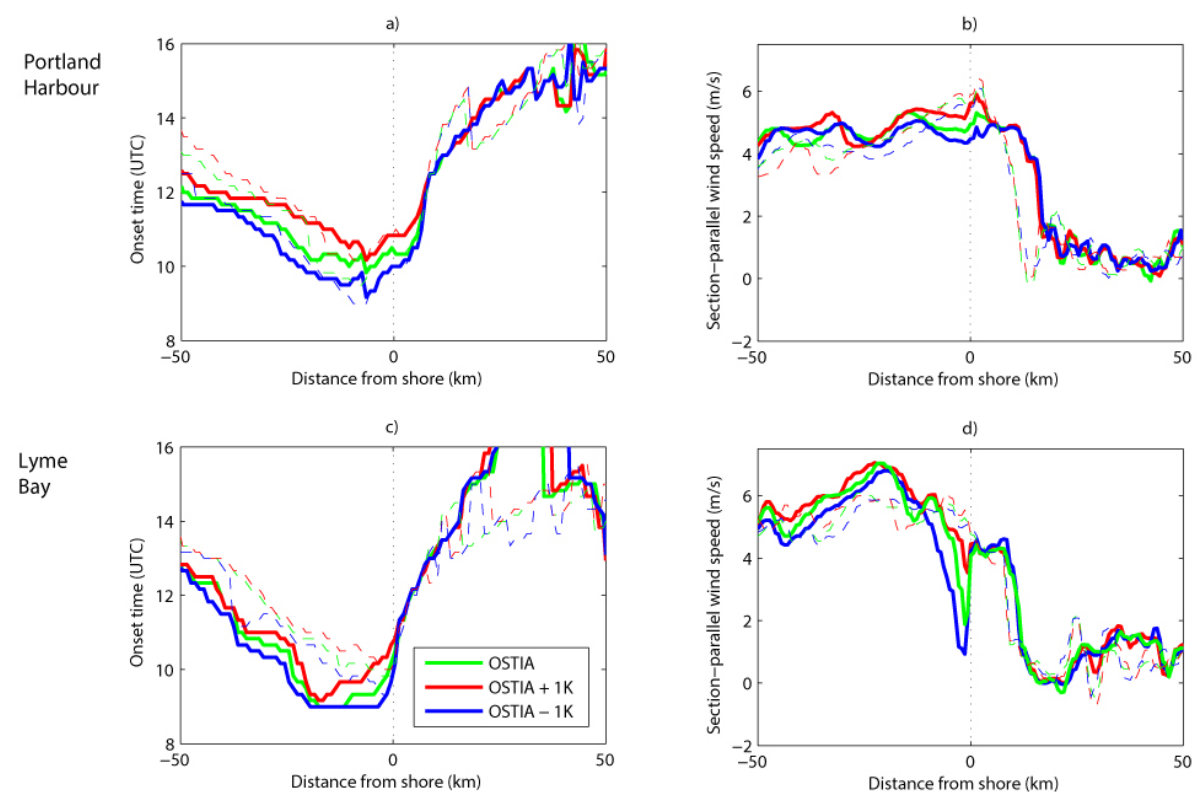

Fig. 7. Sea breeze onset time (left column) and $10 \mathrm{~m}$ southwesterly wind component at 15:00 UTC (right column) along SW-NE-oriented sections passing through Portland Harbour (first row) and Lyme Bay (second row). Experiments with orography are indicated by the solid lines, and experiments without orography are indicated by the dashed lines. The locations of Lyme Bay and Portland Harbour are shown in Fig. 1a, and the location of the cross sections are shown in Fig. 4b. Lines are plotted using model output with 10 min temporal and $1 \mathrm{~km}$ horizontal spacing. Positive distance is inland and negative distance is offshore.
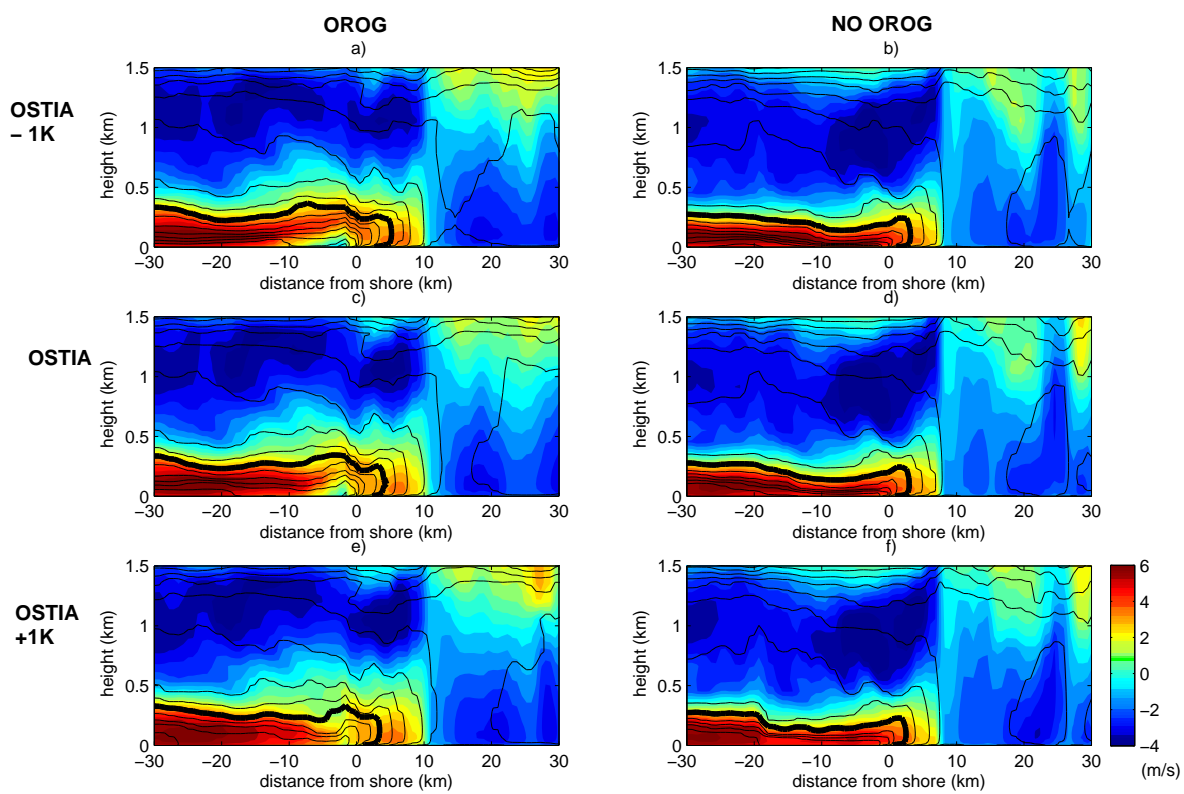

Fig. 8. Vertical cross sections along a SW-NE transect through Lyme Bay at 15:00 UTC. The section-parallel wind component (filled contours) and isentropes (black contours, every $0.5 \mathrm{~K}$ ) are shown for each of the perturbed-SST simulations with and without orography. For reference, the thick black contour is the $291 \mathrm{~K}$ isentrope. Height corresponds to the terrain following model coordinate. 
behind the sea breeze front is $1-2 \mathrm{~K}$ colder in the cold SST experiments than in the warm SST experiments.

Stagnation of flow on the windward side of an obstacle can be understood in terms of the Froude number $\mathrm{Fr}=$ $U /(H N)$, where $N$ is the Brunt-Väisällä frequency, $U$ is the speed of the flow approaching the obstacle, and $H$ is the height of the barrier. The Froude number characterizes the relative importance of the flow inertia versus the resistance to lifting imposed by the static stability. A Froude number less than 1 is associated with blocking. A stronger flow would discourage blocking, whereas a stronger static stability would encourage blocking. For all of the experiments shown in Fig. 8, the onshore flow is approximately $6 \mathrm{~ms}^{-1}$ (see also Fig. 7d). However, the static stability varies significantly between the cold and warm SST experiments (for the runs with orography). The vertical temperature gradient in the cold experiment (inferred from Fig. 8a, using values $30 \mathrm{~km}$ offshore) is approximately $3.5 \mathrm{~K} / 200 \mathrm{~m}$ in the lowest $200 \mathrm{~m}$; in the warm experiment the gradient (inferred from Fig. 8e) is approximately $2 \mathrm{~K} / 200 \mathrm{~m}$. The corresponding Froude numbers are estimated to be approximately 1.25 in the cold SST experiment (i.e., right at the blocking threshold) and 1.65 in the warm SST experiment. Consequently, the calm zone that exists in Lyme Bay is consistent with partial flow blocking by orography enhanced by colder SST. Although the estimated Froude number is greater than one in all experiments, partial flow stagnation may still be expected (Reinnecke and Durran, 2008). The estimate of the Froude number is complicated by the nonuniformity of the upstream flow and the irregularity of the orography profile; nevertheless, the decrease in Froude number for colder SST to near unity value indicates that partial blocking is responsible for the calm zone.

\section{Conclusions}

The effect of SST and coastal orography on the sea breeze along the south coast of England has been investigated in a set of convection-permitting numerical simulations with the MetUM. It has been shown that the interaction of the sea breeze with coastal orography results in a narrow region of decreased wind speeds immediately offshore. Termed the "calm zone", the decreased winds are a consequence of partial blocking of the onshore sea breeze circulation by the orography. The existence of the calm zone was verified by observations. The calm zone only formed in those model runs with coastal orography. Furthermore, the extent of blocking was most pronounced in those model runs having the coldest SST. Although a colder SST would normally generate a stronger sea breeze circulation - an effect which by itself would discourage blocking of the flow - a colder SST also results in a more stable marine boundary layer, and the increased static stability of the onshore flow encourages blocking. In the simulations presented in this study, the increased static stability dominated the effect of increased onshore sea breeze winds and, as a consequence, blocking was more pronounced for the colder SST experiments.

The perturbation SST of $\pm 1 \mathrm{~K}$ used in this study is representative of the SST errors that are likely to occur in operational NWP forecasts that do not incorporate diurnally varying SST. As Tang (2012) demonstrated, the errors can indeed be much larger locally (e.g., $4 \mathrm{~K}$ as seen in Fig. 2c). The study presented in this paper has emphasized that even a small SST perturbation can have dramatic consequences for the structure of the sea breeze circulation on small scales, while the overall sea breeze structure is not significantly altered. Small changes in SST can be amplified due to the strong regulating influence of static stability in the marine boundary layer on the sea breeze structure, such as in the case of onshore winds interacting with coastal topography. We therefore conclude that inclusion of the diurnal cycle of SST can be crucial for correct representation of the sea breeze in regional-scale NWP forecasts, particularly when the Froude number is near unity. The diurnal cycle of SST might render a diurnally fixed SST too cold during the afternoon, which would potentially lead to a calm zone that is too strong in a model forecast. Accurate forecasts of the sea breeze are critical to many end users including those in the marine, littoral, and air-quality control industries.

The study presented in this paper focussed on a single case study along the south coast of England. The conclusions drawn from this investigation are likely to be relevant to other coastal locations in the midlatitudes that have coastal orography and modest diurnal SST variation. An informal survey of sea breeze days along the English south coast (not shown) reveals that the calm zone is a regular phenomenon in Lyme Bay. Nevertheless, analysis of additional cases in different locations is required to determine how frequently the sea breeze is blocked by coastal topography, both along the English south coast and elsewhere, and whether the characteristics of this blocking are sensitive to the details of the synoptic-scale flow. Additionally, a more detailed analysis of boundary-layer processes is required to elucidate the precise manner by which the SST and sea breeze inflow interact to modify the structure of the marine boundary layer.

Acknowledgements. The authors thank Y. Tang for discussions that led to the formulation of the experiments presented in this paper. J. Chagnon is supported by the National Centre for Atmospheric Science (NCAS) under the Weather Directorate.

Edited by: H. Wernli 


\section{References}

Arritt, R. W.: The effect of water surface temperature on lake breezes and thermal internal boundary layers, Bound.-Lay. Meteorol., 40, 101-125. 1987.

Davies, T., Cullen, M. J. P., Malcolm, A. J., Mawson, M. H., Staniforth, A., White, A. A., and Wood, N.: A new dynamical core for the Met Office's global and regional modelling of the atmosphere, Q. J. Roy. Meteor. Soc., 131, 1759-1782, doi:10.1256/qj.04.101, 2005.

Donlon, C. J., Martin, M., Stark, J. D., Roberts-Jones, J., Fiedler, E., and Wimmer, W.: The Operational Sea Surface Temperature and Sea Ice analysis (OSTIA), Remote Sens. Environ., 116, 140-158, doi:10.1016/j.rse.2010.10.017, 2011.

Finkele, K.: Inland and offshore propagation speeds of a sea breeze from simulations and measurements, Bound.-Lay. Meteorol., 87, 307-329, 1998.

Gregory, D. and Rowntree, P. R.: A mass flux convection scheme with representation of cloud ensemble characteristics and stability-dependent closure, Mon. Weather Rev., 118, 14831506, 1990.

Kawai, Y. and Wada, A.: Diurnal Sea Surface Temperature Variation and Its Impact on the Atmosphere and Ocean: A Review, J. Oceanogr., 63, 721-744, 2007.

Kawai, Y., Otsuka, K., and Kawamura, H.: Study on Diurnal Sea Surface Warming and a Local atmospheric Circulation over Mutsu Bay, J. Meteor. Soc. Jpn., 84, 725-744, 2006.

Lock, A. P., Brown, A. R., Bush, M. R., Martin, G. M., and Smith, R. N. B.: A new boundary layer mixing scheme. Part I: Scheme description and single-column model tests, Mon. Weather Rev., 118, 3187-3199, 2000.

Miller, S. T. K., Keim, B. D., Talbot, R. W., and Mao, H.: Sea breeze: Structure, forecasting, and impacts, Rev. Geophys., 41, 1011, doi:10.1029/2003RG000124, 2003.
Pett, R. W. and Tag, P. M.: The Sea-Breeze-Induced Coastal Calm Zone as Revealed by Satellite Data and Simulated by a Numerical Model, Mon. Weather Rev., 112, 1226-1233, doi:10.1175/1520-0493(1984)112<1226:TSBICC>2.0.CO;2, 1984.

Porson, A., Steyn, D. G., and Schayes, G.: Sea-breeze scaling from numerical model simulations, part II: Interaction between the sea breeze and slope flows, Bound.-Lay. Meteorol., 122, 31-41, 2007.

Reinecke, P. A. and Durran, D. R.: Estimating Topographic Blocking Using a Froude Number When the Static Stability Is Nonuniform. J. Atmos. Sci., 65, 1035-1048, doi:10.1175/2007JAS2100.1, 2008.

Risien, C. M.: Climatology of Global Ocean Winds, http://cioss. coas.oregonstate.edu/cogow/index.html (last access: 5 August 2013), 2013.

Segal, M., and Pielke, R. A.: On the effect of water temperature and synoptic flows on the development of surface flows over narrowelongated water bodies, J. Geophys. Res., 90, 4907-4910, 1985.

Steele, C. J., Dorling, S. R., von Glasow, R., and Bacon, J.: Idealized WRF model sensitivity simulations of sea breeze types and their effects on offshore windfields, Atmos. Chem. Phys., 13, 443461, doi:10.5194/acp-13-443-2013, 2013.

Tang, Y. : The Effect of Variable Sea Surface Temperature on Forecasting Sea Fog and Sea Breezes: A Case Study, J. Appl. Meteorol. Clim., 51, 986-990, 2012.

Wilson, D. R. and Ballard, S. P.: A microphysically based precipitation scheme for the UK Meteorological Office Unified Model, Q. J. Roy. Meteor. Soc., 125, 1607-1636, 1999. 